\title{
A (r)evolução dos costumes: nada mudou, tudo mudou'
}

\author{
Maria Eunice Maciel $^{2}$
}

Résumé: Cet article étudie les transformations ayant eu lieu pendant le processus de mobilisation des années 1960 dont les événements de 1968 sont la référence centrale. Ces modifications des coutumes et du mode de vie constituent l'un des principaux héritages de cette époque où la contestation et la transgression étaient des axes fondamentaux des mouvements en cours et où, en conséquence de ces mobilisations, il se produisit des changements significtifs dans de nombreux aspects de la vie quotidienne dans le monde occidental, entre autres dans les domaines de la famille, du sexe, du corps, de l'inclusion sociale, des droits et de l'art.

Palavras-chave: juventude, costumes, mobilizações.

Já foi dito que, após maio de 1968, "nada mudou e tudo mudou”. Embora possa parecer contraditória, a frase faz todo sentido quando se tenta pensar sobre os acontecimentos que ficaram conhecidos como Maio de 68 (que não se trata apenas do mês de maio e nem apenas de 1968) referindo-se a um eventochave, que tornou-se um ícone, uma referência aos movimentos sociais do final do século XX.

Porém os acontecimentos de maio não foram isolados, eles inscreveram-se nos chamados movimentos dos anos 60 - um conjunto de mobilizações que ocorreram em diversas partes do mundo, dos EUA à Tchecoslováquia, da França ao Brasil.

No transcorrer dos anos 60, tiveram lugar movimentos que poderiam ser caracterizados como de "cunho revolucionário", pondo em questão não apenas a ordem política, mas também diversos aspectos da vida social. A dimensão política destes movimentos foi e ainda é objeto de dissecações e polêmicas, mas cabe também refletir sobre um outro aspecto não menos importante (embora muitas vezes considerado menor ou secundário), aquele que se refere às transformações no que se convencionou chamar de costumes, ou seja, as maneiras de viver e de pensar.

As lutas pelos direitos das então chamadas "minorias" tais como os negros (assim chamados ao invés do politicamente correto "afro-descendentes" e dos quais o "black power e o "black panther americanos foram expoentes), as transformações relacionadas com a estrutura familiar, as relações pais-filhos (com uma nova visão do papel e da imagem da mulher e da criança), com a liberação sexual (foi a geração que primeiro pode usar da pílula anticoncepcional), e a relação dos indivíduos com seus corpos (o que se refere desde o vestuário, como a mini-saia até o uso de drogas), o questionamento da autoridade; a relação com o meio ambiente foram referências que tiveram naquele momento um impulso particular sob uma perspectiva transgressora.

É bom lembrar que não foram os anos 60 que inventaram uma série de referências que a eles ficaram ligados, tais como o feminismo, a liberdade sexual, a consciência ecológica ou a luta contra a discriminação. Porém, deram um novo sentido e acabaram por transformar o cotidiano e o modo de vida das pessoas.

Os acontecimentos desse período (levando em conta que toda a periodização é arbitrária) já foram caracterizados como movimentos de juventude, já que os jovens foram seus protagonistas principais - o mundo era jovem.

Embora não tenham ficado restritos ao movimento estudantil, foi a juventude e, em especial, a de classe média urbana, que representou sua parte mais visível. Se jovem pode ser considerado como uma categoria muito fluída, também pode ser entendido no quadro dos acontecimentos que traziam em si determinados anseios e expectativas desta parcela da população, a considerada jovem, mas que repercutiam mais amplamente na sociedade. As idéias de contestação e transgressão que eram levantadas pela juventude permearam quase todos os aspectos da vida social trazendo à baila questões que acabaram gerando novos hábitos e comportamentos.

Tão importante eram estas questões que a primeira reivindicação do Maio de 68 francês foi um pedido apresentado pelos estudantes para se permitir que os rapazes fossem ao quarto das meninas no campus da

\footnotetext{
1 Versão revisada, corrigida e levemente aumentada do texto originalmente publicado em: PONGE, Robert (Org.). 1968, o ano das muitas primaveras. Porto Alegre: Unidade Editorial da Secretaria Municipal de Cultura da Prefeitura Municipal, 1998. p. 129-133.

${ }^{2}$ Maria Eunice Maciel é professora de Antropologia no IFCH da UFRGS.
}

Organon, Porto Alegre, n 47, julho-dezembro, 2009, p.65 - 71 
universidade de Nanterre. ${ }^{3}$ No Brasil também foi assim sendo que em vários lugares não havia classes de "turmas mistas", sendo separadas as de homens e as de mulheres.

Já foi dito que, nesta época, "os cabelos cresceram e as saias encurtaram". Trata-se de uma observação que pode parecer extremamente secundária, porém seu sentido não pode ser menosprezado. A indumentária é uma forma de comunicação e, se hoje pode parecer simplório que o tamanho dos cabelos e das saias tenha gerado tanta polêmica, nos anos 60 tanto um quanto outro eram símbolos de rebeldia e manifestações de não-conformismo, chocando-se com padrões estabelecidos.

Em um contexto onde as mulheres não podiam trabalhar de calças compridas ${ }^{4}$ (embora fossem usadas há muitas décadas, inclusive por ícones do cinema como Marlene Dietrich), vestir mini-saia e jeans era algo escandaloso. As primeiras jovens que, em Porto Alegre, atreveram-se a sair de mini-saia pela rua da Praia no centro de Porto Alegre foram alvo de chacotas e acabaram na delegacia.

Os cabelos compridos dos homens também foram alvo de chacotas sendo alguns, inclusive, vítimas de violência. "Cabeludo" tornou-se algo pejorativo incluindo-se na marginalidade.

Os protagonistas dos movimentos dos anos 60 eram fruto do baby boom (são mesmo chamados de boomers) e do crescimento econômico do pós-guerra. Tendo nascido num mundo onde a autoridade dos pais era quase incontestável, os castigos físicos ainda eram tidos como estratégias educativas, sexo era tabu e os papéis feminino e masculino regiam-se, predominantemente, por normas tradicionais, encontravam uma situação que poderia ser sintetizada no título de uma antiga série de TV: Papai sabe tudo.

Não ouvidos nas decisões que os atingiam, os jovens de então estavam, em alguns países (tais como os EUA e a Inglaterra, salvo engano), na situação de não poder votar nem comprar bebida alcóolica antes do vinte e um anos, porém podiam ser mandados para a guerra, caso que ficava evidente nos EUA dos anos 60 envolvidos com o Vietnã e expresso na dor, raiva e desespero dos veteranos que voltavam da guerra, denunciavam suas atrocidades e chegavam a devolver suas medalhas.

No Brasil, um certo modelo relacionado com o futuro dos filhos era recorrente e atingia em especial a classe média. Expresso na frase "a obrigação dos adultos é trabalhar e das crianças é estudar", preconizava a busca de estabilidade e ascensão social via o estudo e a "carreira", ou traduzindo: numa profissão que propiciasse uma determinada renda e status. O estudo era assim uma forma de "encaminhar os filhos", entendendo por isso atingir um ideal que pouco levava em consideração as aspirações pessoais dos jovens, mas sim o desejo parental, (situação esta que, em parte, perdura até hoje) e que tinha na obtenção do diploma universitário um passo importante.

Mas este quadro aqui traçado de forma simplificada trazia em si ambigüidades e contradições. É certo que transformações estavam ocorrendo, porém davam-se aos poucos e variavam conforme o país e conforme a classe ou grupo social. Mesmo no que se refere à educação de crianças e jovens, livros que preconizavam uma educação mais aberta e franca (como, por exemplo, o do Dr. Sock0 tinham grande difusão e influenciaram uma parcela dos pais, contribuindo para mudar a atitude tradicional.

Aos poucos, a nova geração educada para obedecer a autoridade, numa situação onde os adultos diziam o que fazer e como pensar começou a inquietar-se sendo que, em alguns lugares e em determinadas parcelas da sociedade, expressou-se em atitudes desafiadoras.

A rebeldia teve um lugar e momento privilegiados nas universidades onde a politização não ficou só em debates mas passou ao enfrentamento. Os movimentos tiveram como marcos as rebeliões estudantis que sucediam-se na França, EUA, Alemanha, Itália, Japão, México e, é claro, Brasil. Porém, estas revoltas não eram apenas fruto de uma politização de setores universitários - os quais foram ponta de lança dos movimentos a partir de idéias de justiça social e influência do marxismo -, mas inscreveram-se num quadro mais geral de rebelião da juventude que, em sua disposição para a mudança, veio a contestar valores e procedimentos estabelecidos e legitimados.

Grandes manifestações estudantis agitaram diversas partes do mundo sendo respondidas com violência, fenômeno verificado não apenas no Brasil (que a partir de 1964 vivia sob o regime militar, o que fazia com que o caráter político tivesse uma força enorme sobre a juventude, chamada a lutar pela liberdade), mas em diversas partes do globo.

Embora a contestação ao que era ensinado e como era ensinado tenha sido importante no questionamento estudantil, este não ficou restrito aos aspectos relacionados ao ensino, mas representou uma revolta contra toda uma situação social. No Brasil, a contestação apareceu junto com o enfrentamento contra a repressão da ditadura militar e do AI-5, resultando nos processos, expulsões e para muitos, prisão, tortura e exílio. Nos EUA, misturou-se com a luta pelos direitos civis e contra a guerra do

\footnotetext{
${ }^{3}$ Segundo Gilles Lapougue. "Maio 68: Um ano que continua a resistir a qualquer teoria ou interpretação". Estado de São Paulo, $11 / 05 / 2008$.

${ }^{4}$ Segundo depoimentos, às professoras da rede estadual de ensino era permitido usar calças compridas no auge do inverno, desde que acompanhadas por casacão.
} 
Vietnã. Na França, pegou de surpresa o governo do general De Gaulle. Foi o momento, também, da primavera de Praga.

Embora a contestação ao que era ensinado e como era ensinado tenha sido importante na luta estudantil, este movimento não ficou restrito aos aspectos relacionados ao ensino, mas transformou-se em uma revolta contra toda uma situação social. É o período de transgressão em todos os sentidos.

Também é a época em que uma parcela desta juventude (particularmente nos EUA, mas com influência internacional), na esteira da contracultura, tentou criar um modo alternativo de viver. Eram os hippies que, com slogans de paz e amor e roupas exóticas e extravagantes, tentavam colocar-se num campo anti-materialista voltado para a vida comunitária e a natureza, experiência esta que, muitas vezes, acabou dissipada numa cultura de drogas.

Enquanto alguns identificam o período com a contracultura, outros o fazem com o movimento político estudantil. Porém, tanto a contracultura quanto o movimento estudantil, tal como se apresentavam, podem ser vistos como expressões daqueles tempos havendo momentos e espaços de intersecção.

É difícil buscar uma unidade numa situação de tal maneira rica. A década de 60 é o momento do marxismo mas também da Era de Aquário. Do black power e, é sempre bom lembrar, do black is beautiful. É quando sutiãs são queimados, Leila Diniz exibe orgulhosamente sua barriga de grávida na praia. Os muros de Paris trazem "l'imagination au pouvoir!","soyez réalistes, demandez l'impossible" e, é claro, "é proibido proibir" que vira canção de Caetano Veloso. É o tempo de Bob Dylan e John Lennon, Chico Buarque e Caetano Veloso. Misticismo oriental e barricadas, drogas psicodélicas e debates. Woodstock e Sorbonne. Mary Quant e Guevara. Luta e festa.

Porém, seria importante retomar que, nesse momento marcado por ambigüidades e contradições, as idéias circulantes eram reinterpretadas de maneiras diversas conforme lugares e grupos sociais diferentes. O rock, vinculado à idéia de rebeldia no Brasil da politização estudantil construída, em grande parte, via o populismo nacionalista, era tido como expressão do imperialismo norte-americano e contraposto à música brasileira. Ou seja, separava-se a rebelião estudantil "politizada" de uma rebeldia genérica vista como "alienada". Mesmo no Brasil, o Tropicalismo de Caetano e Gil encontrou enormes resistências junto a setores tidos como politizados. Diferentes símbolos e diferentes interpretações.

Se o Maio francês tornou-se um marco dentre as lutas do período, em parte devido à tradição de lutas francesa (na qual, num imaginário difuso, as barricadas e os séculos são confundidos - reis, camponeses, foices e ancinhos com paralelepípedos, intelectuais, Marx e grafite), o 68 brasileiro não foi uma mera transposição, mas possuiu características próprias de luta contra a ditadura.

Não apenas a agitação e ousadia dos anos 60 não era generalizada (o que não quer dizer que fosse algo meramente vanguardista, no sentido redutor e pejorativo do termo) como também os que protagonizaram estes movimentos tinham visões desiguais sobre os diversos aspectos do social (exemplificada pela existência de um conservadorismo nas relações entre homens e mulheres em algumas organizações políticas de esquerda). O que estava ocorrendo não se dava na mesma maneira em São Paulo, Paris e São Francisco; nem mesmo da mesma forma no interior de cada país.

Podemos dizer que as agitações dos anos 60 representaram uma força impulsionadora de transformações - transformações estas que já estavam ocorrendo, mas que, sob o impulso das mobilizações, ganharam uma outra dimensão. Se não resultou na revolução socialista, deixou marcas no sentido da transformação de costumes e valores representada pelas mudanças na família e no casamento, pela nova maneira de encarar o sexo, pelas conquistas das lutas anti-racista, feminista e ecológica. Mais do que isso, deixou o que já foi chamado de sensibilidade.

Em 1964 ocorreu no Brasil a "marcha com Deus pela família e a propriedade". Pensando retrospectivamente, se hoje é um tanto difícil pensar numa nova marcha, não quer dizer que as idéias que a alimentaram tenham deixado de existir e, com outra roupagem, estejam plenamente ativas.

Em 1966, a já extinta revista Realidade que trazia uma pesquisa sobre a juventude e o sexo foi impedida de circular por ser considerada "chocante" e "obscena". Da mesma forma, se hoje ainda se debate se as escolas devem fornecer educação sexual, dificilmente um juiz consideraria uma pesquisa sobre sexo como "obscena".

Muitos são os exemplos que podem ser listados. Numa época onde se discute qual a atitude dos pais quando seus filhos (as) trazem os namorados (as) para dormir em casa, fica difícil explicar que há havia tabus como o da virgindade e que não foi há tanto tempo que foram postos abaixo.

Mas, se as pessoas cantavam "era um garoto, que como eu, amava os Beatles e os Rolling Stones" e acabavam mortas no Vietnã, garotos continuam morrendo em outras guerras.

Sendo inegável que algo mudou, cabe refletir sobre o sentido dos acontecimentos, seus limites e seu impacto social. Para muitos, as décadas seguintes tiveram um certo sabor de ressaca, luto e de desilusão

\footnotetext{
${ }^{5}$ Música cuja versão brasileira ficou famosa através do conjunto musical Os Incríveis em 1967. Em 1970, esse mesmo conjunto também tornou famosa a canção "Eu te amo meu Brasil"(autoria de Dom, da dupla Dom e Ravel) com letra ufanista e utilizada pela ditadura.
}

Organon, Porto Alegre, n 47, julho-dezembro, 2009, p.65 - 71 
(o sonho acabou?), seja por que a revolução não ocorreu, seja por que a vitalidade dos anos 60 retrocedeu. Alguns identificam um possível movimento pendular da história no qual se alternariam momentos libertadores com conservadores conforme as gerações, o que faria com que estivéssemos vivendo, no momento atual, o oposto dos anos 60, com o retorno do conservadorismo com tendências autoritárias, expressos, entre vários aspectos, pelas proibições (fumar, etc), pela necessidade de adotar um "estilo de vida saudável" em uma perspectiva "higienizadora" onde o prazer e o desejo não são levados em consideração, enfim, um neo-conservadorismo. Para outros ainda, a regressão da vida política e o abandono dos ideais de justiça social e de liberdade antes cultivados em troca de estabilidade, adaptação, consumo e sucesso material traria o perigo da perda do que já foi alcançado.

Estas são apenas algumas das interrogações que subsistem e o momento é propício à reflexão, não no sentido do saudosismo de um tempo em que o mundo era jovem, mas entendendo que, afinal, de uma ou de outra forma, o ontem deve explicações ao hoje.

\section{Bibliografia}

MORIN, E.; LEFORT, C.; CASTORIADIS, C. Mai 68: la brèche. Paris: Fayard, 1968.

MATOS, Olgaria C.F. Paris 1968: as barricadas do desejo. São Paulo: Brasiliense, 1981.

LAPOUGUE, Gilles. Maio 68: Um ano que continua a resistir a qualquer teoria ou interpretação, Estado de São Paulo, 11/05/2008 